\title{
CORRECTIONS
}

\section{Journal articles boosting impact factor}

In this Filler article by Marek Kosmulski (BMJ 2011;343:d5917

doi:10.1136/bmj.d5917) the automatic link in the reference

Cite this as: BMJ 2011;343:d6093

(Smith R. Journal accused of manipulating impact factor. BMJ

๑ BMJ Publishing Group Ltd 2011

1997;314:461) connects to the wrong BMJ News item. The

correct link is www.bmj.com/content/314/7079/461.5. 